\title{
Which frugivory-related traits facilitated historical long-distance dispersal in the custard apple family (Annonaceae)?
}

\section{Running title: Long-distance dispersal traits in Annonaceae}

Renske E. Onstein ${ }^{1,2 *}$, W. Daniel Kissling ${ }^{3}$, Lars W. Chatrou ${ }^{4}$, Thomas L.P. Couvreur ${ }^{5}$, Hélène Morlon ${ }^{6} \&$ Hervé Sauquet $^{1,7}$

* Corresponding author: onsteinre@gmail.com

${ }^{1}$ Ecologie Systématique Evolution, Univ. Paris-Sud, CNRS, AgroParisTech, Université ParisSaclay, 91400, Orsay, France;

${ }^{2}$ German Centre for Integrative Biodiversity Research (iDiv) Halle-Jena-Leipzig, Deutscher Platz 5e, 04103 Leipzig, Germany;

${ }^{3}$ Institute for Biodiversity and Ecosystem Dynamics (IBED), University of Amsterdam, P.O. Box 94240, 1090 GE Amsterdam, The Netherlands;

${ }^{4}$ Wageningen University and Research, Biosystematics group, Wageningen, The Netherlands; ${ }^{5}$ IRD, DIADE, Univ Montpellier, Montpellier, France;

${ }^{6}$ Institut de Biologie, École Normale Supérieure, Paris, France;

${ }^{7}$ National Herbarium of New South Wales (NSW), Royal Botanic Gardens and Domain Trust, Sydney, Australia.

\section{Acknowledgements}

We are grateful to Joan Pereira from the Forestry Herbarium in Sandakan for organising the fieldwork in Borneo, and Joel Dawat, Postar Miun, Jeisin Jumian, Tawadong Tangah and Aloysius Laim for assistance in the field. We acknowledge the Sabah Biodiversity Centre (SaBC) for access permits. We also thank Jürg Schönenberger and University of Vienna for hosting the PROTEUS database. Lorenzo Ottaviani, Véronique Normand and Florinde Vessies are acknowledged for their contributions to the trait data. This research was funded by a Swiss National Science Foundation Early Postdoc.Mobility grant (P2ZHP3_161991) to R.E.O. and an Agence Nationale de la Recherche grant (ANR-12-JVS7-0015-01, MAGNIPHY) to H.S. The University of Amsterdam provided support through the Faculty Research Cluster 'Global Ecology' and a starting grant to W.D.K. R.E.O. further acknowledges the support of the German Centre for Integrative Biodiversity Research (iDiv) Halle-Jena-Leipzig funded by the Deutsche Forschungsgemeinschaft (DFG, German Research Foundation) - FZT 118. 


\section{Abstract}

\section{Aim}

Long-distance dispersal has contributed to the disjunct biogeographical distribution of rain forest plants - something that has fascinated biogeographers since Humboldt's time. However, the dispersal 'agent' for these tropical plant lineages remains puzzling. Here, we investigate which frugivory-related traits may have facilitated past intercontinental longdistance dispersal in the custard apple family (Annonaceae), a major vertebrate-dispersed tropical plant family. We hypothesize that long-distance dispersal was associated with the evolution of traits related to dispersal by large-bodied mammals (e.g. large, dull-coloured, 'megafaunal' fruits) and strong-flying, ocean-crossing birds and bats (e.g. dehiscent, moniliform or cauliflorous fruits).

\section{Location}

Global

\section{Taxon}

Annonaceae

\section{Methods}

We used a fossil-calibrated phylogenetic framework to infer the biogeographic history of 234 Annonaceae species (10\%, covering nearly all genera) in relation to the evolution of 15 frugivory-related traits, using maximum likelihood and Bayesian inferences. Furthermore, we used linear and generalized linear models and phylogenetic simulations to test whether ancestral fruit traits during intercontinental dispersal were different from those of other lineages not involved in long-distance dispersal.

\section{Results}

We inferred the ancestral Annonaceae fruits to be small with a single or few small seeds and a small number of fruitlets. These fruits were most probably apocarpous, indehiscent and/or moniliform (i.e. long beads of fruitlets). Furthermore, most of the long-distance dispersal events in Annonaceae occurred via the expanded tropical forests in the Early Cenozoic ('geodispersal'), and were significantly associated with large (c. $3 \mathrm{~cm}$ long), dull-coloured fruits, and short stipes. Additionally, long-distance dispersal was also facilitated by dehiscent, moniliform and non-cauliflorous fruits.

\section{Main conclusions}

We suggest that the evolution of frugivory-related traits associated with dispersal by frugivores that frequently move across large distances and/or barriers, such as large-bodied mammals and strong-flying birds, has contributed to the disjunct tropical biogeographical distribution of Annonaceae, and probably of tropical rain forest plants more generally.

Keywords: Annonaceae, frugivory, functional traits, fruit size, geodispersal, historical biogeography, long-distance dispersal, megafauna, rain forest, vicariance. 


\section{Introduction}

Since the travels of Alexander von Humboldt (1889), the tropical rain forest biome, its diversity, and the disjunct biogeographic distribution of rain forest families, has fascinated biogeographers. Indeed, rain forests comprise an extraordinary plant diversity even though they cover only ca. 7\% of the Earth's surface (Morley, 2000). Numerous major plant lineages, such as palms (Arecaeae), custard apples (Annonaceae) or laurels (Lauraceae), are distributed across all major tropical rain forest realms of the world. These lineages are often physiologically dependent on the humid and hot climatic rain forest conditions (Morley, 2003). Traditionally, it was thought that these intercontinental disjunct distributions of rain forest lineages were the result of 'vicariance' - i.e. the divergence of a once widespread lineage due to the break-up of the Gondwanan supercontinent (Raven \& Axelrod, 1974). However, estimates of divergence times using fossil-calibrated phylogenetic trees have shown that the timing of continental break-up often preceded the timing of lineage divergence associated with the colonization of new continents (Davis et al., 2002; Renner et al., 2010; Couvreur et al., 2011; Baker \& Couvreur, 2013). Long-distance dispersal (e.g. overland dispersal of distances > c. $1000 \mathrm{~km}$ and/or across oceans, Pires et al., 2017) therefore seems the most plausible scenario to explain much of the disjunct distributions of tropical plant lineages. However, it is often unclear by which dispersal mode (e.g. wind, water or animals) tropical plants historically colonized new continents and their rain forests.

Up to $94 \%$ of extant woody tropical rain forest plant species depend on fruit-eating animals ('frugivores') for their seed dispersal (Jordano, 2000), in which frugivores are rewarded by obtaining important nutrients from the fruits they feed on. Rain forest taxa often show high degrees of continental endemism (at species and genus levels) (e.g. palms, Kissling et al., 2012), because intercontinental dispersal by animals, as compared to wind or water, is relatively rare. Indeed, seed dispersal distances, the geographic pattern of seed rain, and the frequency of long-distance dispersal of animal-dispersed taxa are determined by frugivores and their movement behaviours (Nathan et al., 2008; Pires et al., 2017), which may in turn influence the diversification of fleshy-fruited plants (Onstein et al., 2017). Long-distance dispersal is typically rare ("fat-tailed dispersal kernels", Nathan \& Muller-Landau, 2000) and mostly depends on dispersal by large-bodied and wide-ranging frugivorous megafauna (e.g. tapirs [Tapiridae], elephants [Elephantidae]) or strong-flying volant frugivores (e.g. hornbills [Bucerotidae], toucans [Ramphastidae] and fruit bats [Pteropodidae]) (Shanahan et al., 2001; Holbrook et al., 2002; Nathan et al., 2008; Schurr et al., 2009; Pires et al., 2017). It is therefore expected that the largest and most widespread frugivores have been most important for the historical dispersal of tropical plant lineages across continents, but this remains largely untested.

We take a trait-based approach to identify frugivory-related plant traits associated with long-distance seed dispersal, in order to understand which fruits and frugivores may have been most important for historical long-distance dispersal. Large-bodied frugivores, for example, are more likely to perform long-distance seed dispersal and often prefer the largest fruits (Jordano, 2000; Herrera, 2002), thereby increasing the probability of long-distance dispersal for plant species with large fruits compared to those with smaller fruits. Similarly, primates [Primates] disperse seeds over long distances and in multiple habitats due to their large home ranges, and often prefer dull-coloured fruits (Gautier-Hion et al., 1985; Lomáscolo \& Schaefer, 2010), thus increasing the probability of long-distance dispersal for plants with dull-coloured fruits compared to those with bright-coloured fruits. Furthermore, 
strong-flying, volant frugivores, such as certain species of birds (e.g. hornbills) and bats (e.g. fruit bats), are able to cross barriers (e.g. water) and thereby increase the chance for longdistance dispersal (Onstein et al., 2017). Small-seeded fruits with a smooth exocarp, dehiscent or moniliform fruits (i.e. fruits constricted between the seeds, like a necklace) or cauliflory, have been associated with bird- or bat-dispersal, potentially increasing the probability of longdistance dispersal for these fruits (van der Pijl, 1972; Janson, 1983; Gautier-Hion et al., 1985; Lomáscolo et al., 2010). Thus, certain frugivory-related 'trait syndromes' (i.e. sets of correlated traits) (van der Pijl, 1972; Janson, 1983; Gautier-Hion et al., 1985; Lomáscolo et al., 2010) may have predisposed plants for long-distance seed dispersal. However, the role of these traits in relation to the disjunct biogeographical distribution of vertebrate-dispersed plant lineages remains puzzling.

Here, we investigate which frugivory-related functional traits may have facilitated intercontinental long-distance dispersal (i.e. overland dispersal across large distances $>\mathrm{c}$. $1000 \mathrm{~km}$ and/or across oceans, Pires et al., 2017). First, we hypothesize that long-distance dispersal was associated with relatively large fruits with dull colours (i.e. brown, green), and / or large, (pseudo-)syncarpous fruits (in some species described as "megafaunal fruits", Guimarães et al., 2008) (see Figure 1 for examples). These 'mammal' trait syndromes (Figure 2, Janson, 1983) may have enhanced overland long-distance seed dispersal by large-bodied megafauna (e.g. primates, elephants, tapirs, or extinct giant sloths [Megatheriidae] and gomphotheres [Gomphotheriidae]) and thus increase the probability of long-distance dispersal, as compared to small, bright-coloured and / or apocarpous fruits. Second, we expect small seeds, a smooth exocarp, conspicuous, dehiscent or moniliform fruits and / or cauliflorous fruits to be associated with long-distance dispersal (see Figure 1 for examples). These 'bird/bat' trait syndromes (Figure 2, Janson, 1983) may have increased the opportunity for long-distance dispersal by strong-flying, ocean-crossing, volant frugivores as compared to large-seeded, warty or pubescent, indehiscent, non-moniliform and / or non-cauliflorous fruits. As some of these traits may be correlated to other plant traits (e.g. plant height) or present a resource-allocation trade-off (e.g. number vs. size of fruits/seeds and stipe length, Table 1) we also included plant height, growth form, stipe length, fruit and seed number in our analysis.

We test these hypotheses in the custard apple family (Annonaceae, Magnoliales), a major vertebrate-dispersed, globally-distributed plant family, typically confined to the rain forest biome (Keßler, 1993). Annonaceae comprises c. 2400 species and has been well studied from phylogenetic (Chatrou et al., 2012; Guo et al., 2017a), evolutionary (Couvreur et al., 2011; Pirie et al., 2018) and biogeographical (Doyle et al., 2004; Couvreur et al., 2011; Zhou et al., 2012; Thomas et al., 2015) points of view. Furthermore, almost all Annonaceae species are dispersed by animals, ranging from birds, bats, primates, small-bodied mammals (e.g. rodents), and, in some cases, fish (Keßler, 1993). Consequently, the family shows a spectacular diversity of fruit types (Figure 1). We use a newly generated fossil-calibrated phylogenetic framework of Annonaceae, on which we identify long-distance dispersal events using historical biogeographical inference. Furthermore, we reconstruct the ancestral states of fifteen frugivory-related functional traits and use linear and generalized linear models and phylogenetic simulations to identify which fruit traits are significantly associated with longdistance seed dispersal events, as compared to other lineages not involved in long-distance dispersal. 


\section{Molecular dataset}

We sampled 234 Annonaceae species (c. 10\% of total) representing 105 (c. $97 \%$ of total) genera and all four subfamilies, and seven outgroup taxa from related families (Annonaceae was constrained to be monophyletic). For these species, we generated a molecular supermatrix of eight plastid markers as assembled by Chatrou et al. (2012) supplemented with 157 additional sequences for 37 species. For details on the methods, see Chatrou et al. (2012), GenBank numbers for the new sequences are provided in Appendix S1.

\section{Phylogeny and dating}

We reconstructed and dated the Annonaceae phylogenetic tree in BEAST 1.8.2 (Drummond $\&$ Rambaut, 2007). We used the uncorrelated lognormal clock model and a Yule birth prior, but both the Yule and birth-death models inferred similar divergence times (Figure S1). Substitution rates of markers were linked, because all markers are located on the chloroplast and linkage allowed the analyses to reach convergence. We used the GTR + gamma + invariant sites substitution rate model. To date the Annonaceae, we used the fossils Endressinia (most-recent common ancestor of Magnoliaceae and Annonaceae; $113 \mathrm{Ma}$, Mohr \& Bernardes-de-Oliveira, 2004; Massoni et al., 2015a) for the split between Magnoliaceae and Annonaceae, and Futabanthus (89 Ma, Takahashi et al., 2008) for the Annonaceae crown node (for more details, see Appendix S2).

\section{Fruit traits}

We collected data on 15 frugivory-related functional traits (six continuous traits and nine binary traits) for the same Annonaceae species for which sequence data were available, excluding seven species because of lack of fruit trait data (i.e. total trait data for $n=228$ species, $n=3680$ data records scored from 197 sources). These species cover the taxonomic and functional variation in the family (Table 1). Data were gathered from scientific articles, monographs, books, and herbaria in Zurich and Paris (Z, ZT and P) and in the field (Sabah, Borneo, Malaysia, for details see Appendix S1). All traits were assembled in the PROTEUS database (Sauquet, 2016), and the data and data sources are available from Appendix S1 and Dryad XXX.

The fruit measurements relate to the dispersal unit of the plant (Figure 1), because we are interested in the functional role of the fruit in relation to seed dispersal (Table 1), i.e. how the fruit appears to frugivores. For most Annonaceae the dispersal unit is the separate fruitlet ('monocarp'), developed from a carpel that is free in flower (i.e. $n=205$ apocarpous Annonaceae species in our dataset). In some genera (Annona, Anonidium, and genera in tribe Duguetieae) the carpels that are free in flower fuse postgenitally during fruit development (Chatrou \& He, 1999). In Isolona and Monodora, carpels are fused both in flower and fruit stage (Couvreur, 2009). Despite the distinction in morphology and development, we treat the latter two fruit types similarly, as both produce fleshy fruits that are equivalent from the perspective of fruit dispersal (i.e. $n=23$ [pseudo-]syncarpous Annonaceae species in our dataset). We calculated species averages when more than one observation for a trait was recorded. Furthermore, fruit length, fruit number, seed number and maximum plant height were log-transformed to gain normality in the data and to reduce the effect of outliers in the analyses. We performed a principal component analysis (PCA) to evaluate whether the correlation between frugivory-related traits allows us to define trait-syndromes potentially 
associated with particular frugivores using the 'mix.dudi' function in the 'ade4' package in $\mathrm{R}$ (Dray \& Dufour, 2007). In addition, Phylogenetic Generalized Least Squares (PGLS) regressions were performed to further evaluate correlations between these traits (Martins \& Hansen, 1997), resulting in 45 pairwise trait PGLS regressions. The PGLS method estimates phylogenetic signal and regression parameters simultaneously, adjusted for the phylogenetic signal in the model residuals. This was done using the 'pgls' function in the 'caper' $\mathrm{R}$ package (Orme et al., 2018).

\section{Biogeographical inference}

Ancestral geographic ranges of Annonaceae were inferred using the maximum-likelihood approach implemented in BioGeoBEARS (Matzke, 2013). An unconstrained dispersalextinction-cladogenesis model (DEC), which allows for probabilistic inference of models of range expansion (Ree et al., 2005; Ree \& Smith, 2008), as well as a model which additionally allows for cladogenetic dispersal outside the parental areas ('founder-event speciation', using a likelihood ratio-test. All species were coded as present / absent in six geographical regions (Couvreur et al., 2011): North America (including Central America), South America, Asia, Afrotropics, Madagascar and Oceania (including the Pacific islands). We set the maximum number of areas to three to reflect the maximum number of areas occupied by any extant Annonaceae species. The dispersal probability through time between areas was set to equal, to avoid making subjective assumptions on the historical connectivity between continents (but see section on 'classification of long-distance dispersal routes'). The biogeographical reconstructions obtained from the best model were visualized on the MCC tree. These reconstructions were used to identify long-distance dispersal events, i.e. changes in the most likely ancestral area between nodes in the tree. By only evaluating biogeographical reconstructions in the Cenozoic, we excluded vicariance as a possibility to explain biogeographical shifts between ascending and descending nodes.

\section{Classification of long-distance dispersal routes}

We classified long-distance dispersal events of Annonaceae based on the timing and the direction of the events into five routes (for more details see Appendix S2): (1) 'Laurasian geodispersal' (ca. 66-45 Ma) across land bridges during times when the climate was favourable for rain forest taxa at higher latitudes (van Steenis, 1962; Thorne, 1972; Morley, 2000; Morley, 2003). 'Geodispersal' refers to the process whereby species can expand their geographical ranges due to geological or climatic changes (Lieberman, 2005); (2) 'AfroAsian land bridge' enabling migration from Africa to Asia across Arabia via the expanded tropical forests during the Miocene (23-5.3 Ma) (Zachos et al., 2001); (3) 'South AmericaAfrica (SA-A) stepping stones' supporting stepping stone dispersal across islands of the RioGrande Rise and the Walvis Ridge, connecting South America and Africa up until the Oligocene (66-33.9 Ma) (Morley, 2003); (4) 'Pacific island hopping' enabling dispersal between Southeast Asia, Australia and the Pacific islands from the late Miocene-Pliocene onward (ca. $10 \mathrm{Ma}$ ), when Australia and the Asian Plate collided; (5) 'remaining longdistance dispersal' events that could not be assigned to any of the dispersal routes.

Importantly, long-distance dispersal of Annonaceae lineages may have occurred any time along a branch, and the uncertainties in estimated divergence times were therefore taken into account when assigning long-distance dispersal events to dispersal routes (Table S1). 
264 To evaluate which traits may have facilitated historical long-distance dispersal in phylogenetic trees randomly sampled from the posterior of the BEAST analyses, and summarized them on the MCC tree. Inferred probabilities for trait states therefore take topological and divergence time uncertainties into account.

For the binary traits, we used maximum likelihood as well as Bayesian inferences to perform the ancestral state reconstructions. We used the 'multistate' function in BAYESTRAITS v.2 (Pagel \& Meade, 2006) using the 'addMRCA' command followed by a list of species descending from a particular node for which we aimed to infer the ancestral trait state. These descending species do not necessarily have to form a clade in all 100 trees. For the maximum likelihood analysis, we evaluated support for an equal or unequal transition rate model; the unequal transition rate model was supported for six out of nine discrete traits (Table S2). For the Bayesian Markov chain Monte Carlo (MCMC), we used a reversible jump (rjMCMC) hyper prior with an exponential prior between 0 and 100 for $10 \times 10^{6}$ iterations, with a $10 \%$ burn-in. The rjMCMC approach integrates results over the model space and visits models (e.g. equal and unequal transition rate models) and parameters (e.g. RateDev parameter, to get an acceptance rate of changes between $20-40 \%$ ) in proportion to their posterior probability. The hyper prior provides a distribution from which values are drawn to seed the exponential prior (Pagel et al., 2004; Pagel \& Meade, 2006; see Sauquet et al., 2015; and Onstein \& Linder, 2016 for empirical examples).

For the continuous traits, we used the two-step approach in BAYESTRAITS, in which 'random-walk' models (i.e., Brownian motion) for each trait were run on 100 Annonaceae phylogenetic trees, and the average trait value was estimated subsequently for each internal node. Again, the 'addMRCA' command indicated the common ancestor of a group of species, and the MCMC was run for $10 \times 10^{6}$ iterations, with a $10 \%$ burn-in.

\section{Inferring trait-related long-distance dispersal}

To evaluate whether frugivory-related traits involved in historical long-distance dispersal of Annonaceae deviated from ancestral fruits not involved in long-distance dispersal, we combined the data from the biogeographical inference with the reconstructed traits. First, we tested whether fruit traits were different for ancestral lineages involved in long-distance dispersal compared to those not involved in long-distance dispersal, using Welch Two Sample t-tests. It is important to note that the geographical distribution of some of our characters is highly skewed. For example, (pseudo-)syncarpous fruits do not occur in Asia, some occur in Africa, whereas they are abundant in the Neotropics. Moniliform fruits only occur in Africa, Madagascar and Asia, and are totally absent in the Neotropics. Furthermore, as nodes (and inferred trait values on nodes) are correlated in phylogenies, we expect long-distance dispersal events to be non-randomly distributed across the Annonaceae tree (conditional on the presence of frugivory-related character states as opposed to, for example, 'random' opportunities for dispersal). In addition, it is possible that we detect an association between traits and long-distance dispersal using our method when it is not truly there (i.e. type II error) (Maddison \& FitzJohn, 2015). To address these issues, we compared the empirical results against 1000 simulations of long-distance dispersal events across the Annonaceae tree. In each simulation we randomly assigned long-distance dispersal events to branches within the Annonaceae tree (without replacement, and keeping the total number of long-distance dispersal events the same as empirically inferred), and repeated the t-test as described above (i.e. to test for an association between traits and long-distance dispersal). For these 'random' 
311 long-distance dispersals we expected no significant association with frugivory-related traits, and thus we evaluated whether our observed t-value fell outside the $95 \%$ distribution of simulated t-values.

Second, we tested whether fruit traits were different for ancestral lineages involved in the different dispersal routes (Laurasian geodispersal, Afro-Asian land bridge, SA-A stepping stones, Pacific island hopping and the remaining long-distance dispersal). To this end, linear models (LM) were performed, regressing the continuous fruit traits against the dispersal routes. We evaluated whether the model met the model requirements, i.e. normality of residuals and presence or absence of a relationship between the fitted values and, respectively, the observed and residual values. For the discrete traits, generalized linear models (GLM) using a quasibinomial family with a logit link function were performed, using the probability (between 0 and 1) of presence of the traits as the response variables. The quasibinomial family was used in order to adjust the dispersion parameter to match the degrees of freedom in the data. Similarly, as done for the t-tests, we evaluated the effect of type II error rates on our results by repeating the LMs and GLMs after simulating random long-distance dispersal events 1000 times on the Annonaceae phylogeny.

\section{Results}

\section{Phylogeny}

The Annonaceae crown node was estimated to be $96.8 \mathrm{Ma}(89.0-104.6 \mathrm{Ma}$ [ranges reflect the 95\% HPD]), the Ambavioideae 69.9 (50.6 - 86 Ma), the Annonoideae 74.6 Ma (65.6 84.3 Ma) and the Malmeoideae 38.2 Ma (27.9 - 49.8 Ma). More details are available from the MCC tree (Dryad XXX).

\section{Biogeographical inference and dispersal routes}

The DEC $+\mathrm{J}$ model fitted the data significantly better than the DEC model (Log Likelihood of -233 for DEC + J vs. -259 for DEC), indicating that (founder-event) jump dispersal may have been an important process in the biogeographical history of Annonaceae. However, due to issues related to estimation of the $+\mathrm{J}$ parameter (Ree \& Sanmartín, 2018), we present results consistent across both models here (both models gave qualitatively similar results and are presented in the Supporting tables and figures). Both models identified 24 long-distance dispersal events during Annonaceae evolution, which took place throughout the Late Cretaceous and Cenozoic, possibly from c. $70 \mathrm{Ma}$ until as recent as $0.5 \mathrm{Ma}$ (Figure 3, Figure S2, Table S1). These long-distance dispersals took place within all four Annonaceae subfamilies (Anaxagoreoideae, Ambavioideae, Annonoideae and Malmeoideae), and include shifts within the tribes Bocageeae, Xylopieae, Duguetieae, Guatterieae, Annoneae, Uvarieae, Malmeeae and Miliuseae. Our biogeographical inference also shows that the ancestral area for the Annonaceae crown node cannot be reconstructed with confidence, but Africa is the most probable ancestral area for Annonaceae excl. Anaxagoreoideae (Figure 3, Figure S2).

\section{Ancestral fruit trait reconstruction and trait ordination}

The maximum likelihood and Bayesian ancestral state reconstructions of the frugivory-related traits gave qualitatively similar results, and only the Bayesian reconstructions were therefore used in the subsequent analyses. Based on these reconstructions, we inferred the ancestral Annonaceae fruits to be small, placed on short stipes, with a single or a few small seeds and a small number of fruitlets. These fruits were most probably apocarpous, indehiscent and/or 
moniliform. Colour, conspicuousness, exocarp, pubescence and cauliflory showed ambiguous (equivocal) reconstructions at the ancestral nodes. All ancestral state reconstructions are illustrated in Figure S3.

The PCA shows that the frugivory-related traits we hypothesized to be associated to bird, bat or mammal 'syndromes' (see hypotheses) are clustered in trait space, and thus explain distinct parts of the total frugivory-related functional trait variation in Annonaceae (Figure 2). Similar frugivory-related trait syndromes were also recovered with PGLS, i.e. mammal syndromes of (1) few, syncarpous fruits with many seeds, large fruits, large seeds; bird syndromes of (2) many, bright-coloured, small fruits with few, small seeds and long stipes, and (3) dehiscent fruits with small seeds; and a bat syndrome of (4) dull-coloured, cauliflorous fruits (Table S3). This suggests that frugivory-related traits do not evolve independently from each other and that 'dispersal syndromes' may indeed exist, i.e. sets of co-occurring fruit traits that match the behaviour, feeding preferences and morphology of particular types of frugivores.

\section{Trait-related long-distance dispersal}

Taking all Annonaceae long-distance dispersal events together, we found that five (out of 15) of the frugivory-related traits were significantly associated with long-distance dispersal as compared to those lineages not involved in long-distance dispersal (based on $\mathrm{p}<0.05$, for test statistics see Table S4). These long-distance dispersal fruits were, on average, relatively large (c. $3 \mathrm{~cm}$ long) and were subtended by short stipes (c. $0.6 \mathrm{~cm}$ long). Fruits were also more likely to be dull-coloured, moniliform and/or non-cauliflorous (Figure 4, Table S4). Several of these traits are associated with our hypothesized dispersal syndromes (i.e. a mammal syndrome of large fruits, short stipes, dull colours and a bird syndrome consisting of moniliform fruits). Our simulations show that these results are unlikely explained by type II error rates, because our observed t-value linking frugivory-related traits to long-distance dispersal (for those traits that showed empirical significance) falls outside the $95 \%$ distribution of simulated t-values (i.e. after randomly reshuffling long-distance dispersal events across the Annonaceae phylogenetic tree) (Figure S4).

When testing fruit trait associations with any of the five Cenozoic dispersal routes in particular (Laurasian geodispersal, Afro-Asian land bridge, SA-A stepping stones, Pacific island hopping and remaining long-distance dispersal events), we found that nine (out of 15) traits showed a significant association with at least one of these routes (Figure 4, Tables S5 and S6). These traits were few, viz. large fruits on short stipes and a high probability of being syncarpous (associated with Laurasian geodispersal, SA-A stepping stones), dehiscent or moniliform fruits (associated with Laurasian geodispersal, Afro-Asian land bridge, SA-A stepping stones), non-cauliflorous fruits (associated with Pacific island hopping) and dullcoloured fruits (associated with remaining long-distance dispersal events, but only in the $\mathrm{DEC}+\mathrm{J}$ inference). Seed length and seed number may also be associated with long-distance dispersal, but results were inconsistent between biogeographical models (i.e. DEC $+\mathrm{J}$ vs. DEC). For example, small seeds were associated with Pacific island hopping when following inferences from the DEC $+\mathrm{J}$ model, but the DEC model associated seed length with AfroAsian land bridge and SA-A stepping stone dispersal. Similarly, seed number was positively associated with Early Cenozoic geodispersal and stepping stone dispersal following the $\mathrm{DEC}+\mathrm{J}$ model, but was associated with remaining long-distance dispersal events when following inferences from the DEC model (Figure 4, Table S5).

Again, several of these traits could be linked to the hypothesized dispersal syndromes (i.e. a mammal syndrome of large, [pseudo-]syncarpous fruits and dull colours; a 
bird syndrome consisting of dehiscent or moniliform fruits, Figure 2). Furthermore, these results are unlikely to be driven by 'random' opportunities for long-distance dispersal as shown by our simulations, although some uncertainty exists for seed number, seed length, fruit colour, and dehiscent fruits (Figure S5).

\section{Discussion}

In this study, we combined a comprehensive trait database with a comparative phylogenetic approach to identify frugivory-related traits associated with past intercontinental longdistance dispersal in Annonaceae, a major vertebrate-dispersed tropical plant family (Figure 1). We show that most long-distance dispersal occurred in the Early Cenozoic (Figure 3) when climates were warm and rain forests were extended beyond their current ranges (Morley, 2003). These long-distance dispersal events may have been facilitated by the evolution of few, large fruits, short stipes, dull colours, (pseudo-)syncarpy, dehiscent and/or moniliform fruits (Figures 2 and 4). The recurrent evolution of these traits may have predisposed Annonaceae to colonize (new) continents or islands throughout the Cenozoic, through their interactions with wide-ranging and/or ocean-crossing frugivores.

\section{Frugivory-related traits influence long-distance dispersal}

We show that (pseudo-)syncarpous fruits have been associated with long-distance dispersal of Annonaceae in the Early Cenozoic (c. 45-65 Ma), with dispersals from Africa to South America and Asia (Figure 1d, e, Figure 3, Figure 4f). Some of these (pseudo-)syncarpous fruits have been described as 'megafaunal' fruits, as they are $>10 \mathrm{~cm}$ in size and contain several seeds in a juicy, fleshy pulp (Guimarães et al., 2008), similar to for example durians and jackfruits. These species supposedly rely on large-bodied mammals ('megafauna', $>40$ $\mathrm{kg}$ ) such as elephants, primates and tapirs for their seed dispersal (Rogers et al., 2004; Guimarães et al., 2008). This is in line with the idea that megafauna had a central role in the dispersal of early angiosperm seeds (Eriksson et al., 2000; Tiffney, 2004), facilitating Early Cenozoic dispersal of fleshy-fruited plants via the boreotropical route in Laurasia (Morley, 2003; Couvreur et al., 2011). Indeed, palms likely also possessed megafaunal fruits during their Late Cretaceous/Early Cenozoic dispersals across Africa, Asia and South America (Baker \& Couvreur, 2013; Onstein et al., 2018). Furthermore, Asian elephants (Elephas maximus) and their ancestors were proposed as important seed dispersers of several of the megafaunal-fruited Artocarpus (Moraceae) species in South-East Asia (Williams et al., 2017). Many megafaunal seed dispersers, such as South American proboscideans, xenarthrans, and Notoungulata, went extinct in the Late Quaternary (Barnosky et al., 2004), and present-day plants with megafaunal fruits therefore suffer from dispersal limitation, small geographical ranges, and, possibly, extinction (Guimarães et al., 2008; Pires et al., 2017; Onstein et al., 2018).

Generally, our results suggest that large fruits (minimum c. $3 \mathrm{~cm}$ long) growing on short stipes and often dull-coloured (e.g. brown or orange) may have contributed to Cenozoic long-distance dispersal (Figure 1c, f, h and Figure 4a, e, g). These large fruits are found, for example, in extant Uvaria, Monoon or Trigynaea species, or in the Central American species in tribe Miliuseae (especially in the genera Sapranthus and Tridimeris). These fruits are associated with dispersal by relatively large mammals (e.g. primates as suggested for Uvaria, Zhou et al., 2012) and likely contributed to the overland dispersal of Annonaceae throughout 
the Cenozoic, for example via vegetation corridors from Africa to Asia during the Neogene (Figure 3), which coincided with the 'out-of-Africa' dispersal of primates (Zhou et al., 2012; (Casuarius), have gape widths large enough to swallow these fruits.

We also find strong support that moniliform fruits (long strings of bead-like fruitlets, found in e.g. extant Dasymaschalon, Desmos and Monanthotaxis, Wang et al., 2012; Guo et al., 2017b, Figure 1a, Figure 4j), dehiscent fruits (e.g. found in extant Xylopia and Cymbopetalum, Figure 1j, Figure 4i), and (relatively) small seeds (Figure 4c) are traits associated with long-distance dispersal. Both moniliform and dehiscent fruits have been shown to be particularly attractive to birds (Gautier-Hion et al., 1985; Lomáscolo \& Schaefer, 2010; Guo et al., 2017b), although Xylopia has been observed to be fed on by both birds and primates (Johnson \& Murray, 2018). These vertebrate dispersers facilitate germination in these species by removing the aril, the sarcotesta, or both (i.e. structures that inhibit germination) (Stull et al., 2017). The disjunct tropical African/Asian distributions of Dasymaschalon and suggests that dispersal may have occurred via the Afro-Asian land bridge in the Neogene (Figure 3). During this time, frugivorous songbirds (Passeri) showed waves of expansion from Australia through Asia to the rest of the globe (Moyle et al., 2016), possibly facilitating these plant dispersals. Similar bird-dispersed traits may have assisted longdistance dispersal in other tropical families, such as the fleshy berries of Melastomataceae (Renner, 2004b), and the dehiscent fruits of Meliaceae (Koenen et al., 2015). Furthermore, seasonally migratory frugivorous birds, or large-bodied and strong-flying fruit pigeons (Ptilinopus) and frugivorous hornbills (Penelopides) (Holbrook et al., 2002; Kissling et al., 2009) may have assisted historical 'island hopping' of Annonaceae and other tropical plants lineages across Asia, Oceania and the Pacific (e.g. in Cinnamomum, Lauraceae, Huang et al., 2016). Against our expectation, we found that cauliflorous fruits (sometimes associated with bat-dispersal, Table 1), may hinder long-distance dispersal (Figure 4h). Possibly, by growing in the understorey, these fruits may be dispersal limited due to the sedentary behaviour of understory frugivores (Givnish, 2010; Onstein et al., 2017).

Although some of the long-distance dispersal traits identified in this study (e.g. few, large fruits) have been recognized as specialized dispersal syndromes associated with specialized frugivores (i.e. large-bodied animals, highly dependent on fruits, efficient dispersers, feeding on few plant species) (Howe, 1993), some traits (e.g. small seeds, dehiscent fruits) may instead reflect a more generalized, opportunistic dispersal strategy (Howe, 1993). It is therefore expected that a mix of specialized and generalized dispersal agents have been important for the dispersal of vertebrate-dispersed plants (incl. Annonaceae) across continents.

\section{Phylogeny, biogeography and traits: some of the limitations in this study}

Our sampling of Annonaceae (234 / 2400) is sparse and raises the question whether these taxa are sufficiently representative of their distribution and traits to make a meaningful inference. Most (but not all, e.g. Anaxagorea, Xylopia) genera occupy a single area, and most traits show phylogenetic signal (e.g. fruit length, dehiscence, syncarpy and moniliform fruits, Table S7), indicating that most biogeographical and trait transitions happened relatively early during Annonaceae evolution, i.e. throughout the Paleogene (66-23 Ma) and Neogene (c. 23-2.6 $\mathrm{Ma})$, and our sampling ( $97 \%$ of genera were sampled) would be able to capture these events. Undoubtedly, we underestimated the real number of long-distance dispersal events and functional trait transitions, especially during more recent times. Biogeographical studies that target Annonaceae sampling within genera (e.g. Zhou et al., 2012; Guo et al., 2017b; Pirie et 
al., 2018) therefore provide a more comprehensive understanding of Annonaceae dispersal at finer temporal and spatial scales. Importantly, phylogenetically labile traits (e.g. exocarp traits, Table S7, Figure S3) which did not appear significant in the Annonaceae-wide analysis, could provide valuable insights into trait-related long-distance dispersal within genera. Unfortunately, functional trait data for most Annonaceae taxa is currently lacking.

Besides the sampling, we acknowledge uncertainty with respect to divergence times and biogeographic reconstruction, in part due to lack of suitable internal calibrations and informative priors, and the models used to infer ancestral areas and traits remain very simplistic (Ree et al., 2005; Pagel \& Meade, 2006; Drummond \& Rambaut, 2007; Ree \& Smith, 2008; Matzke, 2013). For example, among-lineage and through-time rate heterogeneity (Couvreur et al., 2011; Massoni et al., 2015b) was not taken into account, and analyses could be improved by including fossils directly in the inference, especially to account for, or estimate, extinction. Our phylogenetic reconstructions show that lineages of major Annonaceae clades are inferred to be slightly older than those obtained in previous studies (Su \& Saunders, 2009; Couvreur et al., 2011; but see, Massoni et al., 2015b), although 95\% HPDs overlap, and phylogenetic relationships are similar to previous results (Chatrou et al., 2012; Guo et al., 2017a). The reason for these older ages is likely our use of uniform (as compared to lognormal) distributions for the calibration priors (Sauquet et al., 2012). Furthermore, our biogeographical inference (Figure 3) is consistent with previous biogeographical reconstructions in Annonaceae (for a detailed discussion on historical biogeography in Annonaceae, see Doyle et al., 2004; Couvreur et al., 2011; Zhou et al., 2012; Thomas et al., 2015), but we obtained some differences between the DEC $+\mathrm{J}$ and DEC biogeographical scenarios (Figures 3 and S2), with moderate consequences for traitassociated long-distance dispersal (i.e. inconsistencies for seed size, seed number and fruit colour). Nevertheless, even though the Annonaceae fossil record is poorly understood, our results are consistent with fossil woods from the Paleocene-Eocene of England (Crawley, 2001) and Oregon (Wheeler \& Manchester, 2002), supporting the Laurasian boreotropical dispersal route.

We cannot discard the possibility that historical dispersal happened by modes other than frugivores, as it has previously been argued that long-distance dispersal shows little correlation with fruit trait syndromes (Thomas et al., 2015). Indeed, long-distance dispersal could have happened by rare rafting events on vegetation floats, diaspores in the mud adhering to the feet of birds, or extreme meteorological events. Furthermore, some fruits may be able to float and remain viable for a longer time in salt water (e.g. in invasive mangroveassociated Annona species on Fiji), and may thus have been dispersed by sea currents (Renner, 2004a). Nevertheless, if long-distance dispersal would have been independent from frugivory-related traits, we would expect a random distribution of traits across dispersal events, whereas we detected a significant association between Annonaceae long-distance dispersal and ten out of fifteen frugivory-related traits (Figure 4). Furthermore, our simulation study indicates that this is unlikely driven by neutral / random evolution of these traits on the Annonaceae phylogenetic tree (Figures S4 and S5).

Last, we lack a mechanistic model linking traits and dispersal rates. Although we have taken a trait-based approach to infer the potential frugivores important for long-distance dispersal (Figure 2), actual, present-day dispersers remain unknown for most plant species (incl. Annonaceae) and data availability tends to be localized. Further confidence and precision could therefore be gained in future work addressing these specific limitations. 


\section{Conclusion}

546 Since Humboldt's travels (e.g. 1889), an important finding in the field of historical

547 biogeography has been that long-distance dispersal (vs. vicariance) may have been the rule

548 rather than the exception to explain the pantropical distribution of many plant families (e.g.

549 Myristicaceae, Doyle et al., 2004; Melastomataceae, Renner, 2004b; Monimiaceae, Renner et

550 al., 2010; Arecaceae, Baker \& Couvreur, 2013; Moraceae, Williams et al., 2017).

551 Nevertheless, it has remained puzzling by which mechanism these long-distance dispersal

552 events have occurred (van Steenis, 1962; Thorne, 1972; Morley, 2003). This study contributes to our understanding of the plant traits (such as fruit size, type and colour) and dispersal agents that may have facilitated past intercontinental long-distance dispersal of Annonaceae across the tropical realms. These frugivory-related traits are not unique for this family, and similar traits may thus explain the disjunct distributions of tropical plants more generally. 
Table 1: Fifteen frugivory-related traits measured for Annonaceae species $(n=228)$ and

\begin{tabular}{|c|c|c|c|c|}
\hline & Trait & Description & Functionality & References \\
\hline 1 & Fruit length $(\mathrm{cm})$ & $\begin{array}{c}\text { Length of monocarp or } \\
\text { fruit. }\end{array}$ & $\begin{array}{l}\text { Positively correlated } \\
\text { with frugivore body } \\
\text { size, so that large fruits } \\
\text { rely on large-bodied } \\
\text { frugivores for their } \\
\text { dispersal. }\end{array}$ & $\begin{array}{l}\text { (van der Pijl, 1972; } \\
\text { Jordano, 2000; } \\
\text { Herrera, 2002; } \\
\text { Onstein et al., } \\
\text { 2017; Onstein et } \\
\text { al., 2018) }\end{array}$ \\
\hline 2 & $\begin{array}{l}\text { Fruit(let) } \\
\text { number }\end{array}$ & $\begin{array}{l}\text { Number of monocarps / } \\
\text { fruits attached to fruit } \\
\text { stalk. }\end{array}$ & $\begin{array}{l}\text { Allometric constraint } \\
\text { and / or increase of } \\
\text { dispersal probability. } \\
\text { Trade-off between fruit } \\
\text { size and number. }\end{array}$ & (Howe, 1993) \\
\hline 3 & Seed length $(\mathrm{cm})$ & Length of single seed. & $\begin{array}{l}\text { Positively correlated } \\
\text { with frugivore body } \\
\text { size, so that large seeds } \\
\text { rely on large-bodied } \\
\text { frugivores for their } \\
\text { dispersal. }\end{array}$ & $\begin{array}{l}\text { (van der Pijl, 1972; } \\
\text { Jordano, 2000; } \\
\text { Herrera, 2002; } \\
\text { Onstein et al., } \\
\text { 2017; Onstein et } \\
\text { al., 2018) }\end{array}$ \\
\hline
\end{tabular}

\begin{tabular}{|c|c|c|c|c|}
\hline 4 & Seed number & $\begin{array}{l}\text { Number of seeds per } \\
\text { monocarp / fruit. }\end{array}$ & $\begin{array}{l}\text { Allometric constraint } \\
\text { and / or increase of } \\
\text { dispersal probability. } \\
\text { Trade-off between seed } \\
\text { size and seed number. }\end{array}$ & (Howe, 1993) \\
\hline 5 & $\begin{array}{l}\text { Stipe length } \\
\text { (cm) }\end{array}$ & $\begin{array}{c}\text { Length of stalk bearing } \\
\text { monocarp. }\end{array}$ & $\begin{array}{l}\text { Allometric constraint } \\
\text { and / or increase of } \\
\text { dispersal probability. } \\
\text { Trade-off between fruit } \\
\text { size and stipe length. }\end{array}$ & (Howe, 1993) \\
\hline 6 & $\begin{array}{c}\text { Fruit type } \\
\text { (Apocarpous / } \\
\text { Syncarpous) }\end{array}$ & $\begin{array}{l}\text { Apocarpous fruits consist } \\
\text { of 'monocarps' developed } \\
\text { from a gynoecium that } \\
\text { comprises more than one } \\
\text { free carpel; in (pseudo- } \\
\text { )syncaropous fruits the } \\
\text { carpels are fused either } \\
\text { before or after fertilisation. }\end{array}$ & $\begin{array}{l}\text { Several syncarpous } \\
\text { 'megafaunal' fruits rely } \\
\text { on primates and } \\
\text { (extinct) megafaunal } \\
\text { mammals for their } \\
\text { dispersal, as these } \\
\text { animals are able to tear } \\
\text { apart the fruits. }\end{array}$ & $\begin{array}{l}\text { (Gautier-Hion et } \\
\text { al., 1985; } \\
\text { Guimarães et al., } \\
\text { 2008) }\end{array}$ \\
\hline 7 & $\begin{array}{l}\text { Fruit colour } \\
\text { (Dull / Bright) }\end{array}$ & $\begin{array}{l}\text { Dull monocarps / fruits are } \\
\text { green or brown, bright } \\
\text { fruits are yellow, red, } \\
\text { purple, black or orange }\end{array}$ & $\begin{array}{c}\text { Dull-coloured fruits } \\
\text { have been associated } \\
\text { with dispersal by } \\
\text { mammals, and primates } \\
\text { in particular, as well as } \\
\text { with dispersal by bats. }\end{array}$ & $\begin{array}{c}\text { (van der Pijl, 1972; } \\
\text { Janson, 1983; } \\
\text { Gautier-Hion et } \\
\text { al., 1985; } \\
\text { Lomáscolo \& } \\
\text { Schaefer, 2010) }\end{array}$ \\
\hline 8 & $\begin{array}{c}\text { Conspicuousness } \\
\text { of fruit display }\end{array}$ & $\begin{array}{l}\text { Present when the stipe has } \\
\text { a different colour from the } \\
\text { monocarp, when seeds are } \\
\text { shiny black against a light- } \\
\text { coloured monocarp (i.e. } \\
\text { not brown / black) or } \\
\text { colourful pulp, or when }\end{array}$ & $\begin{array}{l}\text { Conspicuousness of } \\
\text { fruit display has been } \\
\text { associated with bird } \\
\text { dispersal. }\end{array}$ & $\begin{array}{l}\text { (van der Pijl, 1972; } \\
\text { Lomáscolo et al., } \\
\text { 2010; Lomáscolo } \\
\text { \& Schaefer, 2010) }\end{array}$ \\
\hline
\end{tabular}


the aril (surrounding the

seed) has a different

colour from the seed or monocarp.

\begin{tabular}{|c|c|c|c|c|}
\hline 9 & $\begin{array}{l}\text { Fruit exocarp } \\
\text { 'defence' }\end{array}$ & $\begin{array}{l}\text { Present when fruit exocarp } \\
\text { was described as sruphy, } \\
\text { warty, woody, verrucose } \\
\text { and / or pubescent. Absent } \\
\text { when fruit surface was } \\
\text { described as smooth. }\end{array}$ & $\begin{array}{l}\text { Smooth exocarps have } \\
\text { been associated with } \\
\text { bird dispersal, } \\
\text { warty/woody fruits rely } \\
\text { on dispersal by } \\
\text { mammals. }\end{array}$ & $\begin{array}{l}\text { (van der Pijl, 1972; } \\
\quad \text { Janson, 1983) }\end{array}$ \\
\hline 10 & Pubescence & $\begin{array}{l}\text { Hairs or tomentum on fruit } \\
\text { exocarp. }\end{array}$ & $\begin{array}{c}\text { Smooth exocarps have } \\
\text { been associated with } \\
\text { bird dispersal. }\end{array}$ & $\begin{array}{c}\text { (van der Pijl, } \\
1972)\end{array}$ \\
\hline 11 & Cauliflory & $\begin{array}{c}\text { Flowers and fruits grow on } \\
\text { the main trunk. }\end{array}$ & $\begin{array}{c}\text { Cauliflory has been } \\
\text { associated with } \\
\text { dispersal by bats and } \\
\text { understorey frugivores. }\end{array}$ & $\begin{array}{c}\text { (Lomáscolo et al., } \\
\text { 2010) }\end{array}$ \\
\hline 12 & Dehiscence & $\begin{array}{c}\text { Fruit breaks open to } \\
\text { display the (arillate) seeds. }\end{array}$ & $\begin{array}{c}\text { Dehiscence has been } \\
\text { associated with bird } \\
\text { and sometimes primate } \\
\text { dispersal. }\end{array}$ & $\begin{array}{l}\text { (Gautier-Hion et } \\
\text { al., 1985; Johnson } \\
\text { \& Murray, 2018) }\end{array}$ \\
\hline 13 & Moniliform & $\begin{array}{c}\text { Monocarps constricted } \\
\text { between the seeds, like a } \\
\text { necklace. }\end{array}$ & $\begin{array}{l}\text { Moniliform fruits have } \\
\text { been associated with } \\
\text { bird dispersal. }\end{array}$ & $\begin{array}{l}\text { (Wang et al., 2012; } \\
\text { Guo et al., 2017b) }\end{array}$ \\
\hline 14 & $\begin{array}{l}\text { Habit (Shrub / } \\
\text { Tree / Liana) }\end{array}$ & $\begin{array}{l}\text { Trees were defined as } \\
\text { plants that have one main } \\
\text { trunk, shrubs as plants that } \\
\text { may have several trunks, } \\
\text { and lianas as climbers. }\end{array}$ & $\begin{array}{l}\text { Habit relates to display } \\
\text { of fruits in the canopy } \\
\text { (i.e. tree and liana, } \\
\text { unless cauliflorous) or } \\
\text { understorey (i.e. shrub } \\
\text { and liana). This may } \\
\text { relate to dispersal by } \\
\text { e.g. sedentary } \\
\text { understorey frugivores. }\end{array}$ & $\begin{array}{l}\text { (Givnish, 2010; } \\
\text { Onstein et al., } \\
\text { 2017) }\end{array}$ \\
\hline 15 & $\begin{array}{c}\text { Maximum plant } \\
\text { height (m) }\end{array}$ & $\begin{array}{l}\text { Maximum-recorded plant } \\
\text { height (except for lianas). }\end{array}$ & $\begin{array}{l}\text { Plant height is } \\
\text { positively related to } \\
\text { dispersal distance. }\end{array}$ & $\begin{array}{l}\text { (Thomson et al., } \\
\text { 2011) }\end{array}$ \\
\hline
\end{tabular}


564

565

566

567

568

569

570

571

572

573

574

Figure 1: Diversity of vertebrate-dispersed Annonaceae fruit types. Illustration of frugivory-related traits: (a) moniliform fruits, Monanthotaxis sp; (b) conspicuous fruit display, Malmea manausensis; (c) large apocarpous fruits on short stipes, Uvaria muricata; (d) large (pseudo-)syncarpous fruit with several seeds, Duguetia confinis; (e) large syncarpous fruit, Monodora myristica; (f) large apocarpous fruits on short stipes, Uvaria klainei; (g) dehiscent fruits, Xylopia Africana; (h) large apocarpous fruits on short stipes with several seeds, Uvaria klainei. Photos were taken from World Annonaceae

(http://annonaceae.myspecies.info/); photo credit: L.W. Chatrou (a), T.L.P. Couvreur (b, c, eh), J. van der Maesen (d).

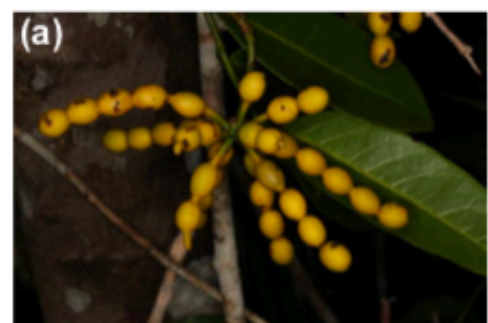

\section{(d)}
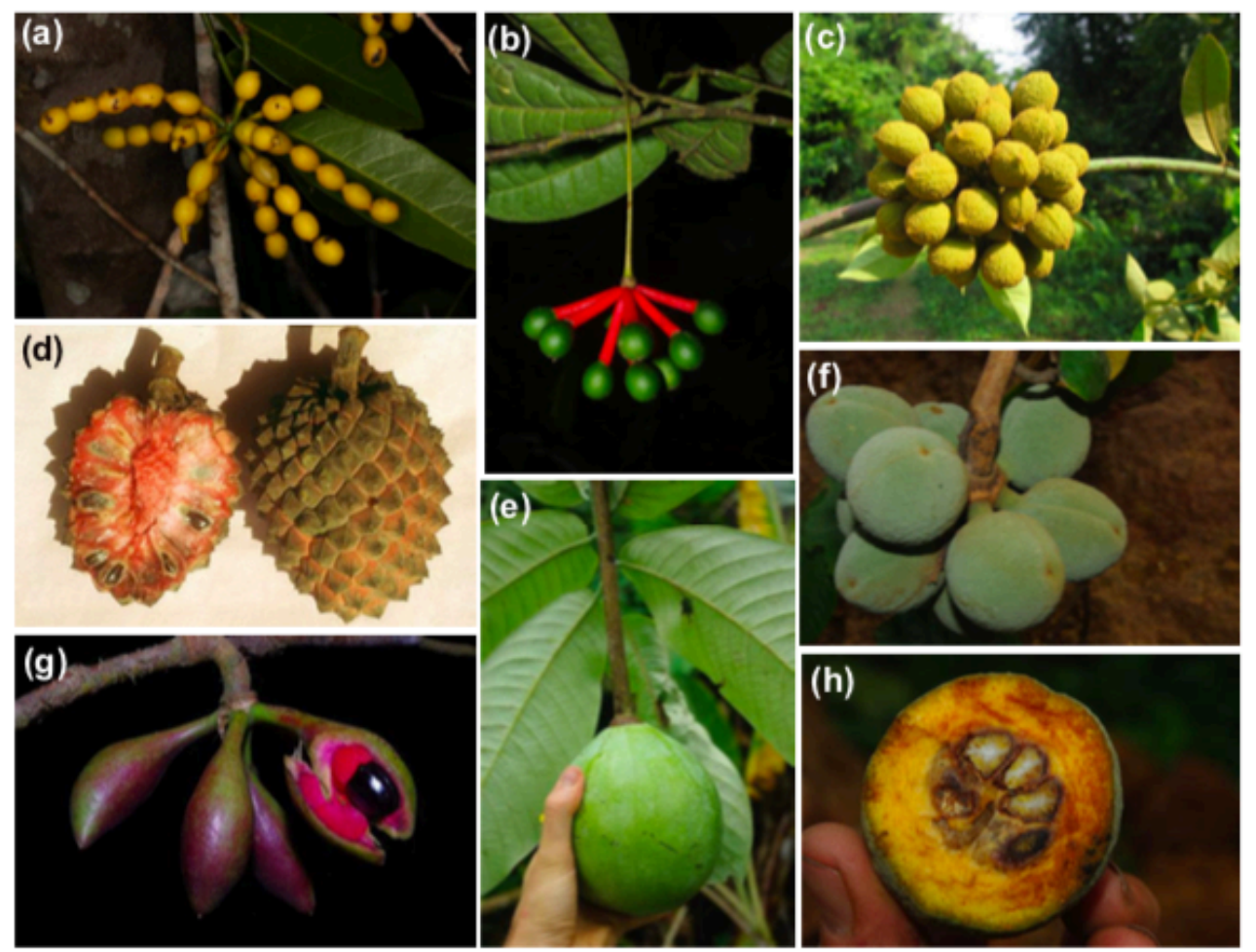
Figure 2: Ordination illustrating the frugivory-related trait syndromes in Annonaceae. Principal component analysis (PCA) of the 10 functional traits which were significantly associated with long-distance dispersal in Annonaceae. Grey dots indicate the position of the species in the ordination ( $n=133$ species without any missing trait data). The animal silhouettes (toucan, bat, and elephant) illustrate our expectation with respect to fruit traits and primary seed dispersers, i.e. bird, bat or (large) mammal fruit traits (see introduction). The ordination shows that traits are correlated and explain distinct variation in trait space, potentially related to bird, bat or mammal trait 'syndromes'. The amount of total variation explained by principal components $\mathrm{PC} 1$ and $\mathrm{PC} 2$ is indicated at the axes.

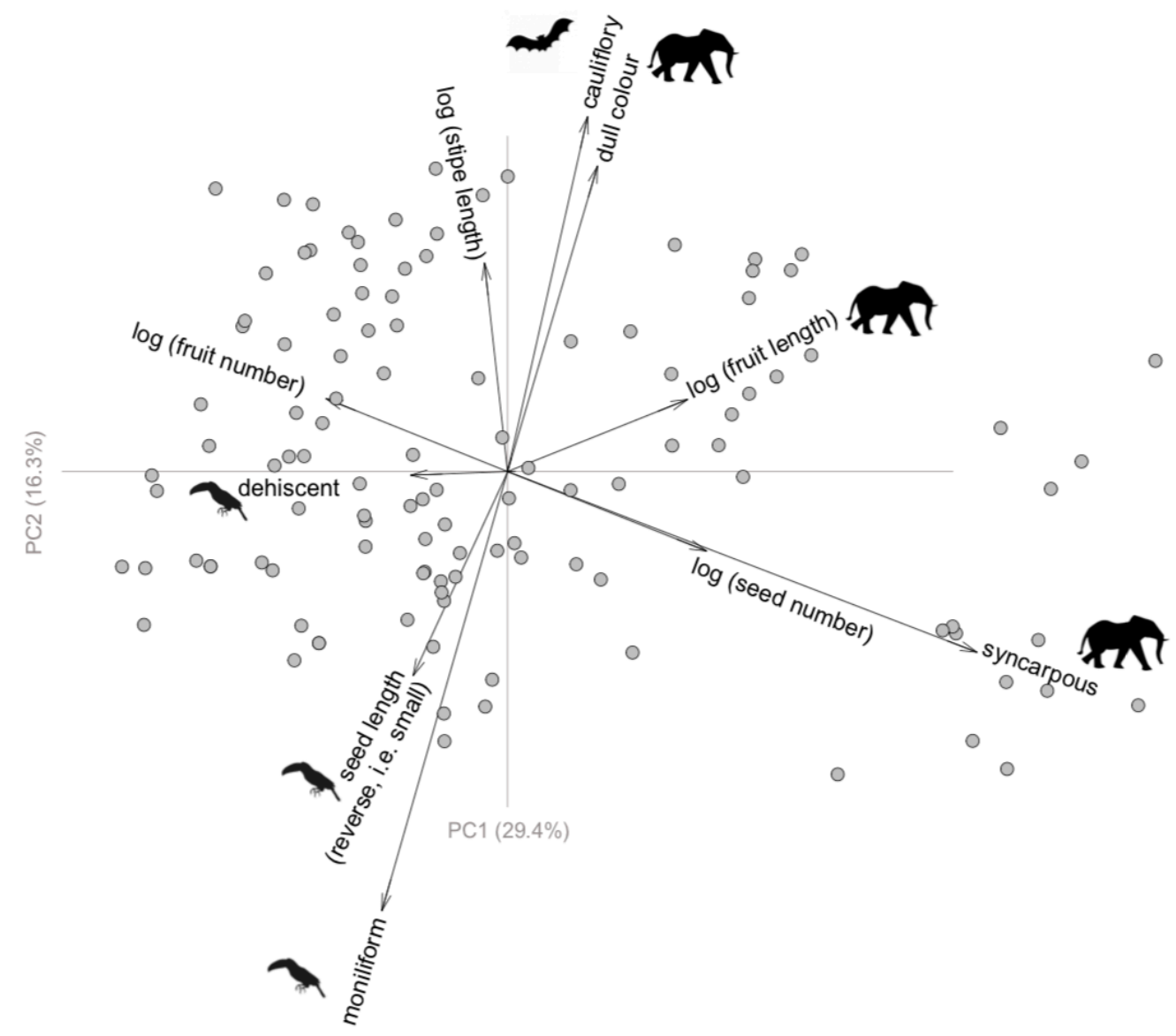


Figure 3: Annonaceae biogeographical inference. The biogeographical reconstruction under the DEC $+\mathrm{J}$ model (dispersal $=0.0008$, extinction $=0$, jump-dispersal $=0.0166$ ) on the Annonaceae maximum clade credibility (MCC) tree visualizes the 24 long-distance dispersal events (dashed branches). The pie-charts indicate the most probable ancestral area(s) (Africa, Asia, Pacific, North America, South America, Madagascar). The long-distance dispersal routes (Laurasian geodispersal, Afro-Asian land bridge, South America-Africa stepping stones and Pacific island hopping) are shown for the respective time periods. The subfamilies are indicated at the tips.

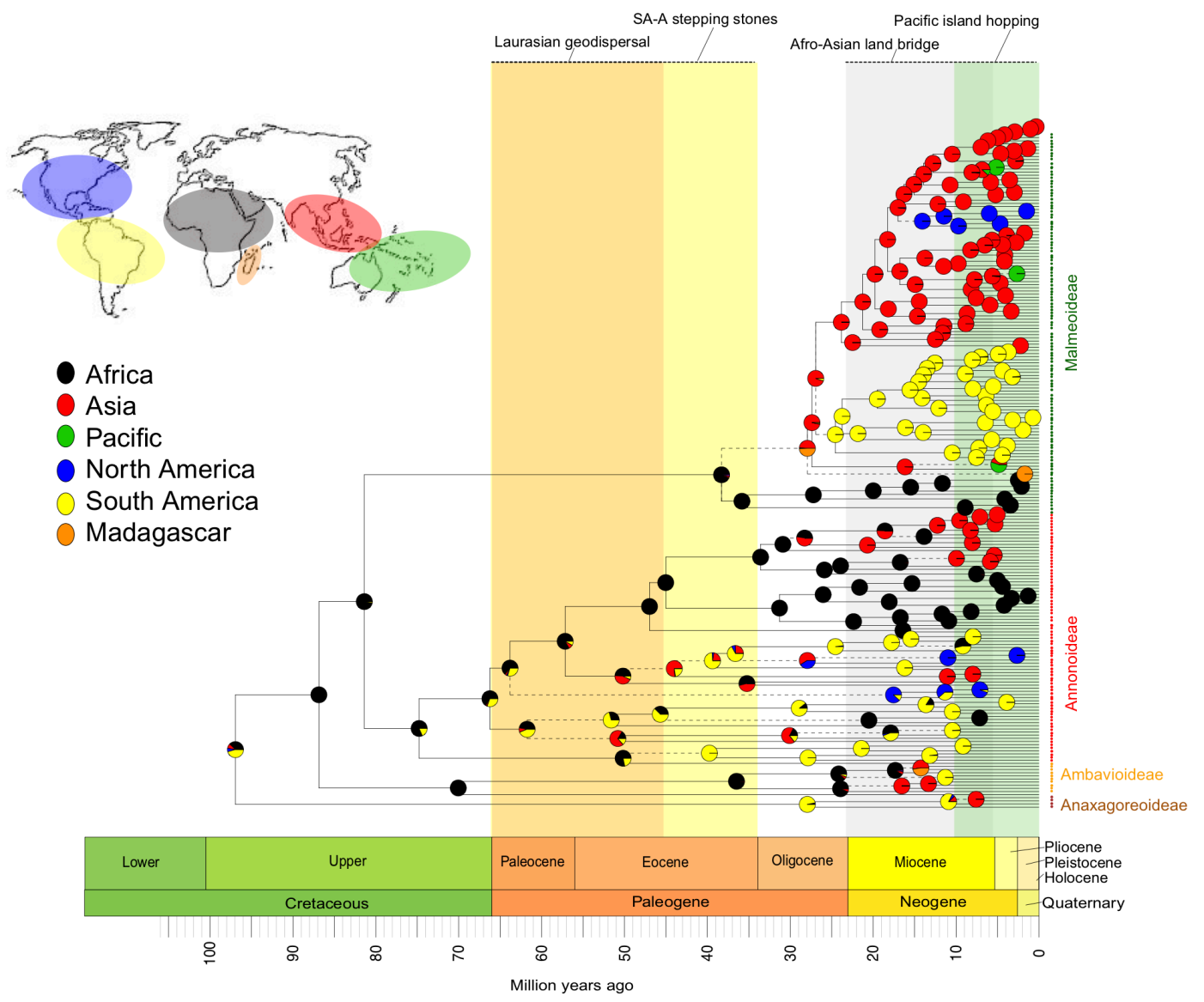


Figure 4: Frugivory-related traits associated with intercontinental long-distance dispersal in Annonaceae. The average value of a trait (continuous traits, a-e) or the probability of the presence of a trait (binary traits, $\mathrm{f}-\mathrm{j}$ ) is indicated for long-distance dispersal events and dispersal routes as compared to Annonaceae lineages not involved in long-distance dispersal, based on ancestral state reconstructions and biogeographical inference from the $\mathrm{DEC}+\mathrm{J}$ model. The traits associated with dispersal routes (represented by colours other than grey) significantly deviating from Annonaceae not involved in long-distance dispersal (grey) are inferred with linear models (continuous, a-e) or generalized linear models (binary traits, fj). The red asterix indicates effects significantly supported by both the DEC and DEC $+\mathrm{J}$ models, a green asterix if only supported by DEC $+\mathrm{J}$ and a black asterix if only supported by DEC. Box-and-whiskers indicate average, $95 \%$ distribution and outliers of trait values. LDD $=$ long-distance dispersal.
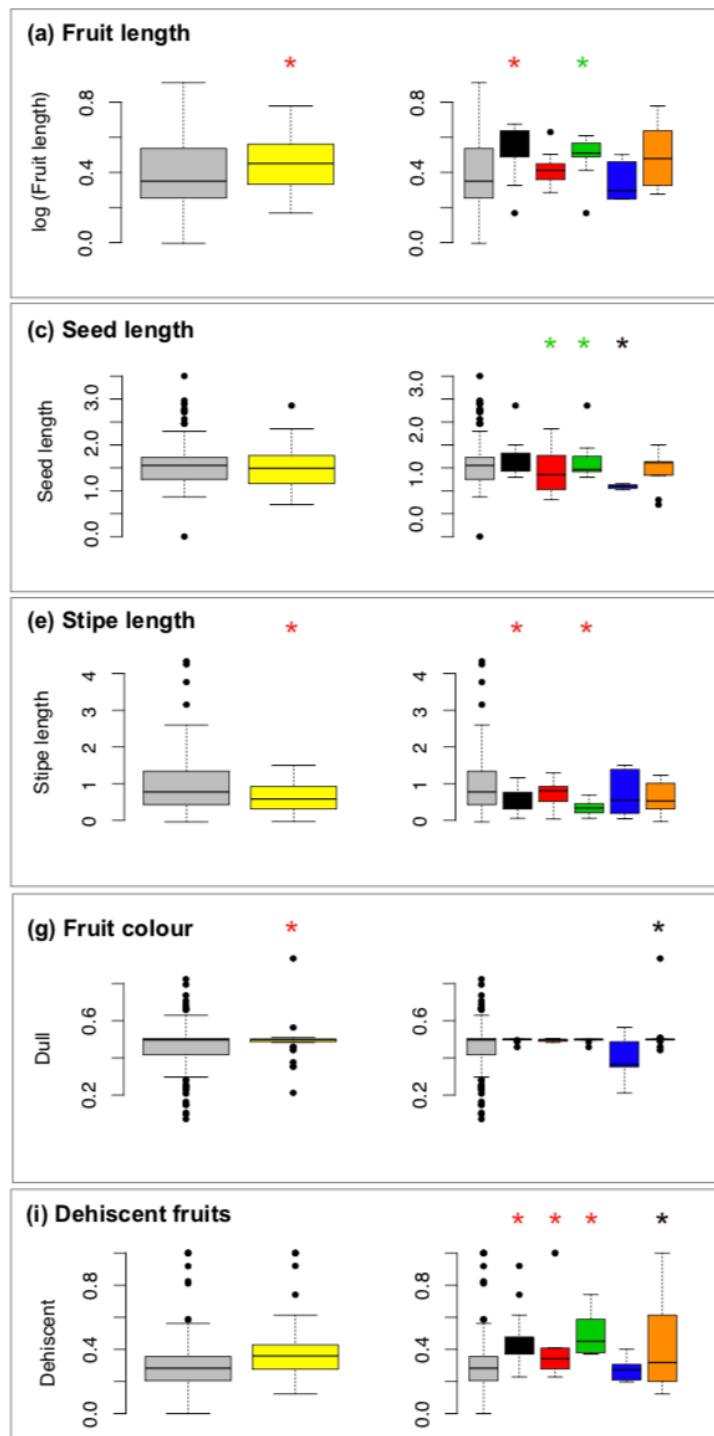

611
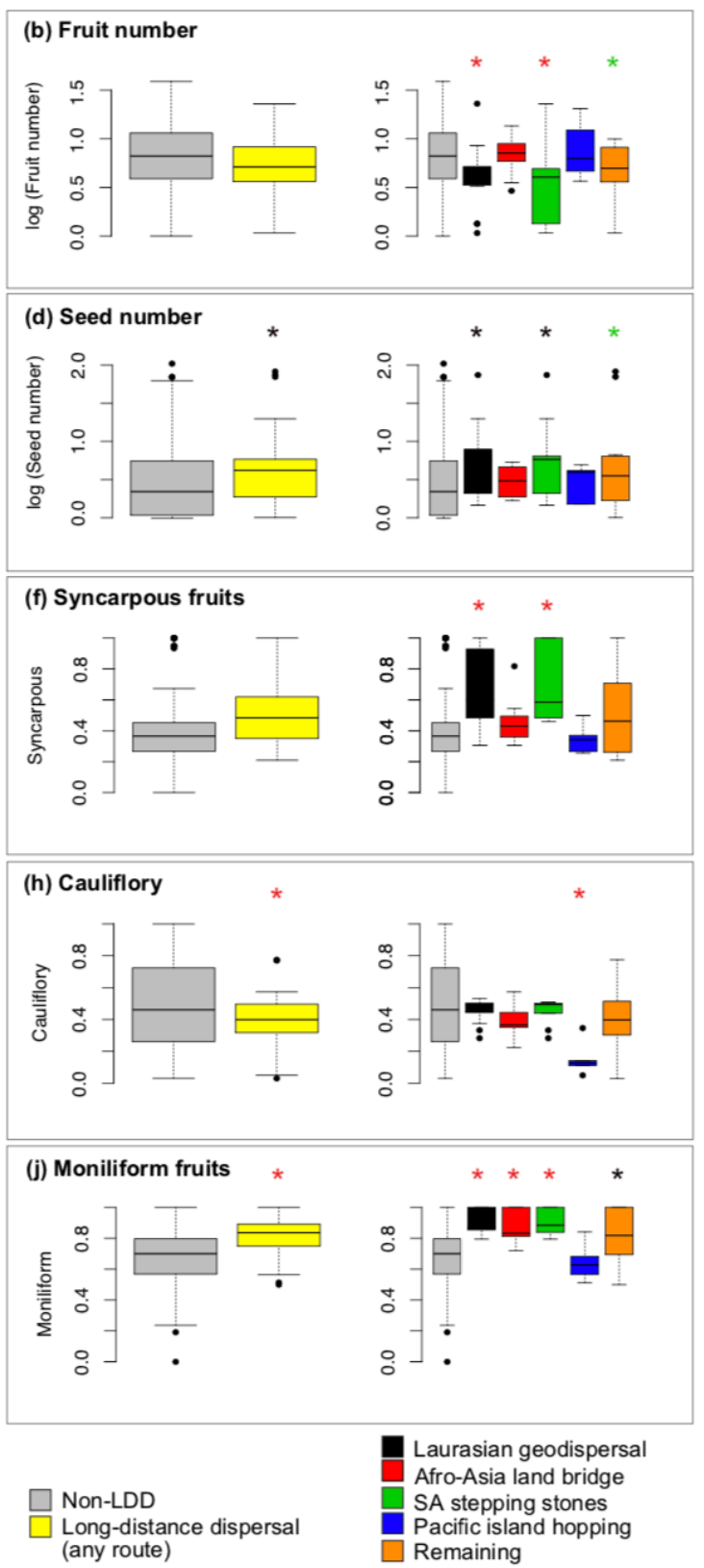
Baker, W.J. \& Couvreur, T.L.P. (2013) Global biogeography and diversification of palms sheds light on the evolution of tropical lineages. I. Historical biogeography. Journal of Biogeography, 40, 274-285.

Barnosky, A.D., Koch, P.L., Feranec, R.S., Wing, S.L. \& Shabel, A.B. (2004) Assessing the causes of Late Pleistocene extinctions on the continents. Science, 306, 70-75.

Chatrou, L.W. \& He, P. (1999) Studies in Annonaceae XXXIII. A revision of Fusaea (Baill.) Saff. Brittonia 51, 51, 181-203.

Chatrou, L.W., Pirie, M.D., Erkens, R.H.J., Couvreur, T.L.P., Neubig, K.M., Abbott, J.R., Mols, J.B., Maas, J.W., Saunders, R.M.K. \& Chase, M.W. (2012) A new subfamilial and tribal classification of the pantropical flowering plant family Annonaceae informed by molecular phylogenetics. Botanical Journal of the Linnean Society, 169, 5-40.

Couvreur, T.L.P. (2009) Monograph of the syncarpous African genera Isolona and Monodora (Annonaceae). Systematic Botany Monographs, 87, 1-150.

Couvreur, T.L.P., Pirie, M.D., Chatrou, L.W., Saunders, R.M.K., Su, Y.C.F., Richardson, J.E. \& Erkens, R.H.J. (2011) Early evolutionary history of the flowering plant family Annonaceae: steady diversification and boreotropical geodispersal. Journal of Biogeography, 38, 664-680.

Crawley, M. (2001) Angiosperm woods from British Lower Cretaceous and Palaeogene deposits. Special Papers in Palaeontology, 66, 1-100.

Davis, C.C., Bell, C.D., Mathews, S. \& Donoghue, M.J. (2002) Laurasian migration explains Gondwanan disjunctions: Evidence from Malpighiaceae. Proceedings of the National Academy of Sciences, 99, 6833-6837.

Doyle, J., Sauquet, H., Scharaschkin, T. \& Le Thomas, A. (2004) Phylogeny, molecular and fossil dating, and biogeographic history of Annonaceae and Myristicaceae (Magnoliales). International Journal of Plant Sciences, 165, S55-S67.

Dray, S. \& Dufour, A.-B. (2007) The ade4 Package: Implementing the duality diagram for ecologists. 2007, 22, 20.

Drummond, A.J. \& Rambaut, A. (2007) BEAST: bayesian evolutionary analysis by sampling trees. BMC Evolutionary Biology, 7

Eriksson, O., Friis, E.M. \& Löfgren, P. (2000) Seed size, fruit size, and dispersal systems in Angiosperms from the Early Cretaceous to the Late Tertiary. The American Naturalist, 156, 47-58.

Gautier-Hion, A., Duplantier, J.M., Quris, R., Feer, F., Sourd, C., Decoux, J.P., Dubost, G., Emmons, L., Erard, C., Hecketsweiler, P., Moungazi, A., Roussilhon, C. \& Thiollay, J.M. (1985) Fruit characters as a basis of fruit choice and seed dispersal in a tropical forest vertebrate community. Oecologia, 65, 324-337.

Givnish, T.J. (2010) Ecology of plant speciation. Taxon, 59, 1326-1366.

Guimarães, P.R., Jr., Galetti, M. \& Jordano, P. (2008) Seed dispersal anachronisms: rethinking the fruits extinct megafauna ate. PLoS ONE, 3, e1745.

Guo, X., Tang, C.C., Thomas, D.C., Couvreur, T.L.P. \& Saunders, R.M.K. (2017a) A megaphylogeny of the Annonaceae: taxonomic placement of five enigmatic genera and support for a new tribe, Phoenicantheae. Scientific Reports, 7, 7323.

Guo, X., Hoekstra, P.H., Tang, C.C., Thomas, D.C., Wieringa, J.J., Chatrou, L.W. \& Saunders, R.M.K. (2017b) Cutting up the climbers: Evidence for extensive polyphyly in Friesodielsia (Annonaceae) necessitates generic realignment across the tribe Uvarieae. Taxon, 66, 3-19.

Herrera, C.M. (2002) Seed dispersal by vertebrates. Plant-animal interactions: an evolutionary approach (ed. by C.M. Herrera and O. Pellmyr), pp. 185-208. John Wiley \& Sons.

Holbrook, K.M., Smith, T.B. \& Hardesty, B.D. (2002) Implications of long-distance movements of frugivorous rain forest hornbills. Ecography, 25, 745-749. 
Howe, H.F. (1993) Specialized and generalized dispersal systems: where does 'the paradigm' stand? Vegetatio, 107, 3-13.

Huang, J.-F., Li, L., van der Werff, H., Li, H.-W., Rohwer, J.G., Crayn, D.M., Meng, H.-H., van der Merwe, M., Conran, J.G. \& Li, J. (2016) Origins and evolution of cinnamon and camphor: A phylogenetic and historical biogeographical analysis of the Cinnamomum group (Lauraceae). Molecular Phylogenetics and Evolution, 96, 33-44.

Janson, C.H. (1983) Adaptation of fruit morphology to dispersal agents in a Neotropical forest. Science, 219, 187-189.

Johnson, D.M. \& Murray, N.A. (2018) A revision of Xylopia L. (Annonaceae): the species of tropical Africa. PhytoKeys, 97, 1-252.

Jordano, P. (2000) Fruits and frugivory. Seeds: the ecology of regeneration in plant communities 2 (ed. by M. Fenner), pp. 125-166.

Keßler, P. (1993) Annonaceae. The families and genera of vascular plants, Vol. 2. Magnoliid, Hamamelid and Caryophyllid families. (ed. by K. Kubitzki, J. Rohwer and V. Bittrich), pp. 93-129. Springer Verlag, Berlin.

Kissling, W.D., Böhning-Gaese, K. \& Jetz, W. (2009) The global distribution of frugivory in birds. Global Ecology and Biogeography, 18, 150-162.

Kissling, W.D., Eiserhardt, W.L., Baker, W.J., Borchsenius, F., Couvreur, T.L.P., Balslev, H. \& Svenning, J.-C. (2012) Cenozoic imprints on the phylogenetic structure of palm species assemblages worldwide. Proceedings of the National Academy of Sciences, 109, 7379-7384.

Koenen, E.J.M., Clarkson, J.J., Pennington, T.D. \& Chatrou, L.W. (2015) Recently evolved diversity and convergent radiations of rainforest mahoganies (Meliaceae) shed new light on the origins of rainforest hyperdiversity. New Phytologist, 207, 327-339.

Lieberman, B.S. (2005) Geobiology and paleobiogeography: tracking the coevolution of the Earth and its biota. Palaeogeography, Palaeoclimatology, Palaeoecology, 219, 2333.

Lomáscolo, S.B. \& Schaefer, H.M. (2010) Signal convergence in fruits: a result of selection by frugivores? Journal of Evolutionary Biology, 23, 614-624.

Lomáscolo, S.B., Levey, D.J., Kimball, R.T., Bolker, B.M. \& Alborn, H.T. (2010) Dispersers shape fruit diversity in Ficus (Moraceae). Proceedings of the National Academy of Sciences, 107, 14668-14672.

Maddison, W.P. \& FitzJohn, R.G. (2015) The unsolved challenge to phylogenetic correlation tests for categorical characters. Systematic Biology, 64, 127-136.

Martins, E. \& Hansen, T. (1997) Phylogenies and the comparative method: a general approach to incorporating phylogenetic information into the analysis of interspecific data. The American Naturalist, 149, 646-667.

Massoni, J., Doyle, J. \& Sauquet, H. (2015a) Fossil calibration of Magnoliidae, an ancient lineage of angiosperms. Palaeontologia Electronica, 18, 1-25.

Massoni, J., Couvreur, T.L.P. \& Sauquet, H. (2015b) Five major shifts of diversification through the long evolutionary history of Magnoliidae (angiosperms). BMC Evolutionary Biology, 15, 49.

Matzke, N.J. (2013) Probabilistic historical biogeography: new models for founder-event speciation, imperfect detection, and fossils allow improved accuracy and modeltesting. Frontiers of Biogeography, 5, 242-248.

Mohr, B.A.R. \& Bernardes-de-Oliveira, M.E.C. (2004) Endressinia brasiliana, a Magnolialean Angiosperm from the Lower Cretaceous Crato Formation (Brazil). International Journal of Plant Sciences, 165, 1121-1133.

Morley, R.J. (2000) Origin and evolution of tropical rain forests. Sons, New York, USA.

Morley, R.J. (2003) Interplate dispersal paths for megathermal angiosperms. Perspectives in Plant Ecology, Evolution and Systematics, 6, 5-20.

Moyle, R.G., Oliveros, C.H., Andersen, M.J., Hosner, P.A., Benz, B.W., Manthey, J.D., Travers, S.L., Brown, R.M. \& Faircloth, B.C. (2016) Tectonic collision and uplift of Wallacea triggered the global songbird radiation. 7, 12709. 
Nathan, R. \& Muller-Landau, H.C. (2000) Spatial patterns of seed dispersal, their determinants and consequences for recruitment. Trends in Ecology \& Evolution, 15, $278-285$.

Nathan, R., Schurr, F.M., Spiegel, O., Steinitz, O., Trakhtenbrot, A. \& Tsoar, A. (2008) Mechanisms of long-distance seed dispersal. Trends in Ecology \& Evolution, 23, 638647.

Onstein, R.E. \& Linder, H.P. (2016) Beyond climate: convergence in fast evolving sclerophylls in Cape and Australian Rhamnaceae predates the mediterranean climate. J. Ecology, 104, 665-677.

Onstein, R.E., Baker, W.J., Couvreur, T.L.P., Faurby, S., Svenning, J.-C. \& Kissling, W.D. (2017) Frugivory-related traits promote speciation of tropical palms. Nature Ecology \& Evolution, 1, 1903-1911.

Onstein, R.E., Baker, W.J., Couvreur, T.L.P., Faurby, S., Herrera-Alsina, L., Svenning, J.-C. $\&$ Kissling, W.D. (2018) To adapt or go extinct? The fate of megafaunal palm fruits under past global change. Proceedings of the Royal Society B: Biological Sciences, 285, 20180882.

Orme, D., Freckleton, R., Thomas, G., Petzoldt, T., Fritz, S., Isaac, N. \& Pearse, W. (2018) Caper: comparative analyses of phylogenetics and evolution in R. $R$ package version 1.0.1. https://cran.r-project.org/package $=$ caper,

Pagel, M. \& Meade, A. (2006) Bayesian analysis of correlated evolution of discrete characters by reversible jump Markov Chain Monte Carlo. The American Naturalist, 167, 808825.

Pagel, M., Meade, A. \& Barker, D. (2004) Bayesian estimation of ancestral character states on phylogenies. Systematic Biology, 53, 673-684.

Pires, M.M., Guimarães, P.R., Galetti, M. \& Jordano, P. (2017) Pleistocene megafaunal extinctions and the functional loss of long-distance seed-dispersal services. Ecography, 41, 153-163.

Pirie, M.D., Maas, P.J.M., Wilschut, R.A., Melchers-Sharrott, H. \& Chatrou, L.W. (2018) Parallel diversifications of Cremastosperma and Mosannona (Annonaceae), tropical rainforest trees tracking Neogene upheaval of South America. Royal Society Open Science, 5, 171561.

Raven, P.H. \& Axelrod, D.I. (1974) Angiosperm biogeography and past continental movements. Annals of the Missouri Botanical Garden, 61, 539-673.

Ree, R.H. \& Smith, S.A. (2008) Maximum likelihood inference of geographic range evolution by dispersal, local extinction, and cladogenesis. Systematic Biology, 57, 2299-3211.

Ree, R.H. \& Sanmartín, I. (2018) Conceptual and statistical problems with the DEC+J model of founder-event speciation and its comparison with DEC via model selection. Journal of Biogeography, 45, 741-749.

Ree, R.H., Moore, B.R., Webb, C.O. \& Donoghue, M.J. (2005) A likelihood framework for inferring the evolution of geographic range on phylogenetic trees. Evolution, $\mathbf{5 9}$

Renner, S.S. (2004a) Plant dispersal across the Tropical Atlantic by wind and sea currents. International Journal of Plant Sciences, 165, S23-S33.

Renner, S.S. (2004b) Multiple Miocene Melastomataceae dispersal between Madagascar, Africa and India. Philosophical Transactions: Biological Sciences, 359, 1485-1494.

Renner, S.S., Strijk, J.S., Strasberg, D. \& Thébaud, C. (2010) Biogeography of the Monimiaceae (Laurales): a role for East Gondwana and long-distance dispersal, but not West Gondwana. Journal of Biogeography, 37, 1227-1238.

Rogers, M.E., Abernethy, K., Bermejo, M., Cipolletta, C., Doran, D., McFarland, K., Nishihara, T., Remis, M. \& Tutin, C.E.G. (2004) Western gorilla diet: A synthesis from six sites. American Journal of Primatology, 64, 173-192.

Sauquet, H. (2016) PROTEUS: A database for recording morphological data and creating NEXUS matrices. Version 1.26. http://eflower.myspecies.info/proteus.

Sauquet, H., Carrive, L., Poullain, N., Sannier, J., Damerval, C. \& Nadot, S. (2015) Zygomorphy evolved from disymmetry in Fumarioideae (Papaveraceae, 
Ranunculales): new evidence from an expanded molecular phylogenetic framework. . Annals of Botany, 115, 895-914.

Sauquet, H., Ho, S.Y.W., Gandolfo, M.A., Jordan, G.J., Wilf, P., Cantrill, D.J., Bayly, M.J., Bromham, L., Brown, G.K., Carpenter, R.J., Lee, D.M., Murphy, D.J., Sniderman, J.M.K. \& Udovicic, F. (2012) Testing the impact of calibration on molecular divergence times using a fossil-rich group: The case of Nothofagus (Fagales). Systematic Biology, 61, 289-313.

Schurr, F.M., Spiegel, O., Steinitz, O., Trakhtenbrot, A., Tsoar, A. \& Nathan, R. (2009) Longdistance seed dispersal. Annual Plant Reviews, 38, 204-237.

Shanahan, M., Harrison, R.D., Yamuna, R., Boen, W. \& Thornton, I.W.B. (2001) Colonization of an island volcano, Long Island, Papua New Guinea, and an emergent island, Motmot, in its caldera lake. V. colonization by figs (Ficus spp.), their dispersers and pollinators. Journal of Biogeography, 28, 1365-1377.

Stull, G.W., Johnson, D.M., Murray, N.A., Couvreur, T.L.P., Reeger, J.E. \& Roy, C.M. (2017) Plastid and seed morphology data support a revised infrageneric classification and an African origin of the pantropical genus Xylopia (Annonaceae). Systematic Botany, 42, 211-225.

Su, Y.C.F. \& Saunders, R.M.K. (2009) Evolutionary divergence times in the Annonaceae: evidence of a late Miocene origin of Pseuduvariain Sundaland with subsequent diversification in New Guinea. BMC Evolutionary Biology, 9, 1-19.

Takahashi, M., Friis, E.M., Uesugi, K., Suzuki, Y. \& Crane, P.R. (2008) Floral Evidence of Annonaceae from the Late Cretaceous of Japan. International Journal of Plant Sciences, 169, 908-917.

Thomas, D.C., Chatrou, L.W., Stull, G.W., Johnson, D.M., Harris, D.J., Thongpairoj, U. \& Saunders, R.M.K. (2015) The historical origins of palaeotropical intercontinental disjunctions in the pantropical flowering plant family Annonaceae. Perspectives in Plant Ecology, Evolution and Systematics, 17, 1-16.

Thomson, F.J., Moles, A.T., Auld, T.D. \& Kingsford, R.T. (2011) Seed dispersal distance is more strongly correlated with plant height than with seed mass. Journal of Ecology, 99, 1299-1307.

Thorne, R.F. (1972) Major disjunctions in the geographic ranges of seed plants. The Quarterly Review of Biology, 47, 365-411.

Tiffney, B.H. (2004) Vertebrate dispersal of seed plants through time. Annual Review of Ecology, Evolution, and Systematics, 35, 1-29.

van der Pijl, L. (1972) Principles of dispersal in higher plants. Springer-Verlag, Würzburg. van Steenis, C.G.G.J. (1962) The land-bridge theory in botany with particular reference to tropical plants. Blumea - Biodiversity, Evolution and Biogeography of Plants, 11, 235-372.

von Humboldt, A. (1889) Personal narrative of travels to the equinoctial regions of America, during the years 1799-1804. G. Bell, London, UK.

Wang, J., Thomas, D.C., Su, Y.C., Meinke, S., Chatrou, L.W. \& Saunders, R.M. (2012) A plastid DNA phylogeny of Dasymaschalon (Annonaceae) and allied genera: Evidence for generic non-monophyly and the parallel evolutionary loss of inner petals. Taxon, 61, 545-558.

Wheeler, E.A. \& Manchester, S.R. (2002) Woods of the Middle Eocene Nut Beds flora, Clarno Formation, Oregon, USA. International Association of Wood Anatomists (IAWA), J 3(suppl), 1-188.

Williams, E.W., Gardner, E.M., Harris, I.I.I.R., Chaveerach, A., Pereira, J.T. \& Zerega, N.J.C. (2017) Out of Borneo: biogeography, phylogeny and divergence date estimates of Artocarpus (Moraceae). Annals of Botany, 119, 611-627.

Zachos, J., Pagani, M., Sloan, L., Thomas, E. \& Billups, K. (2001) Trends, rhythms, and aberrations in global climate $65 \mathrm{Ma}$ to present. Science, 292, 686-693.

Zhou, L., Su, Y.C.F., Thomas, D.C. \& Saunders, R.M.K. (2012) 'Out-of-Africa' dispersal of tropical floras during the Miocene climatic optimum: evidence from Uvaria (Annonaceae). Journal of Biogeography, 39, 322-335. 
832 Biosketch: Renske E. Onstein studies the broad-scale evolution, ecology and biogeography of angiosperms in relation to their functional traits - ranging from the role of fruits and frugivores in tropical rain forest radiations, to sclerophyllous leaf traits in Mediterranean-type ecosystems.

Data availability: Sequences are available from GenBank (Appendix S1). The maximum clade credibility (MCC) tree is available from Dryad XXX. The functional traits for Annonaceae species measured in this study are available from the Supporting Information

840 (Appendix S1) and Dryad XXX.

Author contributions: R.E.O. conceived the ideas with input from W.D.K and H.S.; R.E.O., and all authors discussed the results and commented on the manuscript. 